\title{
How relevant is the place where first-year college students live in relation to the increase in body mass index?
}

Antonio Viñuela ${ }^{1 *}$, Juan José Criado-Álvarez ${ }^{23}$, Javier Aceituno-Gómez ${ }^{4}$, Carlos Durantez Fernández ${ }^{1,}$ José Luis Martín-Conty ${ }^{1}$, Francisco Martín-Rodríguez ${ }^{5}$, Luis Miguel Cano Martín ${ }^{6}$, Clara Maestre Miquel ${ }^{1}$, Begoña Polonio-López ${ }^{1}$, and Alicia Mohedano-Moriano ${ }^{2}$

\footnotetext{
1. Faculty of Health Sciences. University of Castilla-La Mancha, 45600 Talavera de la Reina, Spain; antonio.vinuela@uclm.es (AV);

2. Department of Medical Sciences, School of Health Sciences, University of Castilla-La Mancha, Avenida Real Fábrica de las Sedas, s / n 45600 Talavera de la Reina, Toledo, and Integrated Care Management at Talavera de la Reina, Castilla-La Mancha Health Services, Talavera de la Reina, Toledo Spain; jjcriado@jccm.es (JJCA); alicia.mohedano@uclm.es (AMM)

3. Management of Integrated Attention of Talavera de la Reina. SESCAM. Talavera de la Reina, Spain. Javier.aceituno@uclm.es

4. Faculty of Health Sciences. University of Castilla-La Mancha, 45600 Talavera de la Reina, Spain Carlos.durantez@uclm.es (CDF)

5. Faculty of Health Sciences. University of Castilla-La Mancha, 45600 Talavera de la Reina, Spain; joseluis.MatinConty@uclm.es (JLMC

6. Center for Advanced Clinical Simulation, Faculty of Medicine, University of Valladolid. Advanced Life Support Unit, Emergency Medical Services, Valladolid 47005. Spain; fmartin@saludcastillayleon.es (FMR)

7. Menasalbas Health Center. Toledo Primary Care Management (Toledo, Spain); luismcano@msn.com (LMCM)

8. Faculty of Health Sciences. University of Castilla-La Mancha, 45600 Talavera de la Reina, Spain clara.maestre@uclm.es (CMM)

9. Faculty of Health Sciences. University of Castilla-La Mancha, 45600 Talavera de la Reina, Spain; begona.polonio@uclm.es (BPL)

10. Department of Medical Sciences, School of Health Sciences, University of Castilla-La Mancha, Avenida Real Fábrica de las Sedas, s / n 45600 Talavera de la Reina, Toledo,Spain; Alicia.mohedano@uclm.es (AMM)

* Correspondence: antonio.vinuela@uclm.es Department of Nursing, Physiotherapy and Occupational Therapy. Faculty of Health Sciences Health Sciences. University Castilla-La Mancha. Avenida Real Fábrica de las Sedas, s / 45600 Talavera de la Reina, Toledo, Spain.
}

\begin{abstract}
Objetive: This study analyzes the evolution of the body mass index (BMI) throughout the academic year associated with changes in the lifestyle associated with the place where they live during the course and design lifestyle and health strategies to the university community. (2) Methods: 93 first-year nursing students participated in this study. Data were collected throughout the course by administering self-reported questionnaires about eating habits and lifestyles, weight, and height to calculate their BMI and place of residence throughout the course. Data were analyzed using statistical analysis (Mann-Whitney, Chi-square, student's t- test, repeated-measures analysis of variance, and least significant difference tests). (3) Results: We found that the mean BMI increases significantly throughout the course among all students regardless of sex, age, eating habits or where they live during the course. At the beginning course the mean BMI was $22.1 \pm 3,642$. The mean difference between the beginning of the course and the middle has a value of $p$ value $<0.015$ and between the middle of the course and the end a $\mathrm{p}$ value $<0.009$. The group that increased the most is found among students who continue to live in the family nucleus rather than those who live alone or in residence. Students significantly change their eating and health habits, especially those who live alone or in residences.: (4) Conclusions: There is an increase in BMI among students. It is necessary to carry out seminars or talks that can help students understand the importance of good eating practices and healthy habits to maintain their weight and, therefore, their health, in the short, medium, and long term and acquire a good quality of life.
\end{abstract}

Keywords: adolescents; lifestyles; nutrition; overweight and obesity; food intake 


\section{Introduction}

It is described in the bibliography that throughout the year there is an increase in $\mathrm{BMI}$ in the world population. A group of special interest are young people on their way to adulthood in which there are changes that may be more influential than others, such as changes in lifestyles and changes in lifestyle and eating habits. One of these changes is the move from high school to university. Within this change we find university students who continue to live during the course in the same place of residence during the course, while others live in university residences or alone.

The transition from adolescence to adulthood for many young people coincides with the beginning of their first year of college. For many students, this implies the first prolonged estrangement from the family and the adoption of new responsibilities, among which one of the most important is taking care of their own nutrition [1,2]. Many students begin to live alone or share a flat, while others opt for a residency and some continue to live in the same place as before enrolling in the university. Living alone or shared, involves changes at the organizational, psychological, time management, economic, among others, many new for students [3]. Those who live in a residence, have fewer changes since they have covered many basic needs, meals, laundry or cleaning. Nevertheless, they do not control their own diet, as it is imposed by the residence. On the other hand, those who continue to live in the family home experience fewer changes, mainly those related to the new place of study and the responsibility of starting university. Several authors have described how attachment to family and friends decreases among students who decide to live alone, being replaced by new friends and adapting to a new environment $[4,5]$.

Several factors are involved in the increase in BMI (a simple, inexpensive, non-invasive and rapid measure [6]) among adolescents and young adults, with a greater tendency to gain lean mass in boys compared to girls [7]. . Living in the same house as in previous stages of life, living in a university residence or living alone or sharing a flat may have an impact on the weight gain of students, or it may be that other factors, such as changes in eating habits, imply excessive calorie intake, a sedentary lifestyle, or irregular meal times play a role [8]. Little is known about whether the type of residence significantly affects this increase in BMI.

Food quality, changes in the number of meals, lower intake of fruits and vegetables, and increased consumption of fast food, along with lifestyle changes, can lead to increased BMI, which leads to higher probability of suffering from health problems such as obesity or cardiovascular diseases, among others [2,10-13].

In the transition from high school to college, students acquire less healthy nutritional habits $[14,15]$. The first year is characterized by a decrease in the consumption of fruits / vegetables and an increase in the intake of foods rich in sugar, sodium, and saturated fat [16]. A balanced diet has been shown to contribute to stable health and mental state, and thus better academic performance $[17,18]$. These imbalances are accompanied by inadequate food intake and little or no physical activity, along with poor sleep habits and nutrient-poor diets [19]. Increased consumption of tobacco and alcohol has also been shown, which would also suggest a decrease in their quality of life [14, 18, 20]

The main objective of the study is to find out how the changes in the life of students according to the place of residence influence the first year and analyze the increase in changes in BMI. For this, we evaluated the students in three groups, according to the place where they lived during the course, as well as their self-perceived health, the consumption of tobacco-alcohol, being factors that have been identified with an increase in BMI [2123]. We will also analyze the eating patterns and habits of students, which is known to many to pose many challenges during the first year of university [24].

\section{Materials and Methods}

\subsection{Study design and participants}

This is a longitudinal study carried out on newly enrolled nursing students at the Faculty of Health Sciences of Talavera de la Reina, one of the campuses of the University 
of Castilla-La Mancha (UCLM). All new students were included in the study. The only exclusion criterion was the refusal to participate by any of the students. No other exclusion criteria were established for the very objective of the project. They were informed about the project orally and in writing. All participants were given the documentation on the study, the voluntary nature of their participation and a signed informed consent. Of the 100 students enrolled, 93 agreed to participate. The sample consisted of 80 women (86\%) with a mean age of $20.23 \pm 4,260$ and 13 men $(14 \%)$ with a mean age of $18.46 \pm$ 0.877. The global mean age was $19.98 \pm 4008$ years. Table 1 .

\subsection{Data collection and schedule}

The study design was longitudinal and based on where new students lived during their first academic year and their BMI variation. They were divided into three groups, those who lived in the same house as before starting university, those who lived in a residence hall, and those who lived in a flat alone or shared with others.

Three "ad hoc" questionnaires designed to obtain data on lifestyle and habits were administered. The second questionnaire was administered in February at the end of the first semester and the last one immediately before the end of the course prior to the exams. The data collected included information on sex, age and anthropometric data and place of residence.

The students' BMI (kg / m2) was calculated using self-reported height and weight. Self-reported BMI has been used extensively in previous studies. BMI was measured according to the BMI criteria established by the World Health Organization (WHO) (World Health Organization, 1998).

\subsection{Data on healthy habits}

The surveys collected data on tobacco and alcohol consumption and frequency of use.

They also asked about physical activity performed in gyms or outdoors.

2.4 Statistical analysis

Data analysis was performed using SPSS for Windows (Statistical Package Social Sciences version 15.0). For the statistical analyzes, the parameters were used according to the measurement scales of the variables (simple frequencies, measures of central tendency and standard deviations).

The Kolmogorov-Smirnov test was used to study the normality distribution of the variables, to show that the distributions did not deviate significantly from normal. For the statistical analysis of the independent variables, an ANOVA was performed for the relationship between the continuous normal variable and the nominal variable. In the cases of dichotomous variables, we use the Student's t test. A chi-square test was used to compare the nominal and dichotomous variables. The confidence interval was set at $95 \%$.

\section{Results}

Sample characteristics

This longitudinal study was conducted with a sample of 93 respondents, all of whom were first-year undergraduate nursing students. The sample consisted of 80 women 
$(86 \%)$, with a mean age of $20.23 \pm 4.260$ years, and 13 men $(13 \%)$, with a mean age of 18.46 \pm 0.877 years. The mean age was slightly higher in girls, the global mean age being 19.99 \pm 3.989 years. Table 1 . Table 1 shows the distribution, percentages and standard deviations of the places where the students lived during the year: 21 students $(22.6 \%)$ continued to live in the same house as before starting university, 23 ( 24.7\%) lived in residences and 49 $(52.7 \%)$ lived alone or in shared flats. These numbers did not vary during the academic year. A little more than half of the newbies chose to live alone or share a flat. The table also shows the means and standard deviations of the students' BMI scores for the year. At the beginning of the academic year, the mean BMI was $22.1 \pm 3,642$. The mean of the independent samples of the changes in BMI varied, with the change from BMI-1 to BMI2 ( $p$ value $<0.015$ ) and between BMI-2 and BMI-3 ( $p$ value $<0.009$ ) being statistically significant. By gender, men had a mean BMI of $23.33 \pm 5.07$ and the mean BMI of women was slightly lower than $21.9 \pm 3.38$. These data are not statistically significant $(p>0.05) p=$ 0.251 The mean BMI between men and women increased during the academic year in the three measurement moments, being greater between the first and second measurement than between the second and third. Table 2

It's worth noting that the students' BMIs spanned all ranges. 12 of the students presented values that represented low weight, (16.4\% of the total). Most of the students, however, corresponded to what is known as normal weight 45 students (61.6\%), while $17.8 \%$ of the sample were overweight and obese, a total of 3 students ( $4.2 \%)$. At the end of the course, these values varied, observing that in all cases the weights shifted towards weight gain, which is why we find that the total number of students in healthy weight a total of students $55(61.1 \%)$, overweight $18(20 \%)$ and obesity a total of 8 students $(8.9 \%)$. The only case in which we see a decrease in students is underweight $9(10 \%)$ cases. Table 3

T- Student test used to analyze the differences in means between men and women revealed a significant difference between men and women in the variation between BMI II and III scores. No significant differences related to gender were found for the other variables.

The ANOVA performed to examine the relationship between the type of residence and the variation in weight showed that the place where the students lived had no impact on the variation in BMI between the first and last rounds of the survey.

Therefore, we did not find statistically significant evidence that the type of residence is a cause of an increase in BMI in students throughout the academic year. However, the chi-square test on BMI and type of residence did reveal a statistically significant association between students with a higher BMI, those whose values represented type I and II obesity, and who lived in the family home, $\mathrm{p}<0.05(\mathrm{p}=0.49)$.

Furthermore, we did not find gender-related differences between the increase in BMI and the place of residence. BMI increased similarly in both groups of students, regardless of gender, $\mathrm{p}>0.05$

Health condition 
Students were asked about their perception of their health status at the beginning and end of the academic year. At first, 22 first-year students (23.7\%) perceived their health as very good, 40 (43\%) reported that their health was good, $8(8.6 \%)$ said that their health was average, and 23 The remaining students (24.7\%) either did not answer the question or could not assess their health status. Once the academic year ended, the students were asked about their health again, 44 students (47.3\%) reported that their health status was the same as at the beginning of the course, $23(24.7 \%)$ that their health status had improved, and 17 (18.3\%) perceived their health worse. The remaining 7 students (9.7\%) did not answer the question or could not assess their health status. It should be noted that almost half of the students reported feeling that their health was the same as at the beginning of the year, which implies that their lifestyle had remained constant throughout the academic year. However, 13 students (14\%) were smokers or started smoking during the year and $14(15.1 \%)$ reported drinking more alcohol than at the beginning of the academic year. Table 4 .

We found no association in the self-perceived health of the students during the academic year. Most students (48.5\%) perceive that their health is the same throughout the year, compared to $23.5 \%$ who feel better and $23.5 \%$ who perceive their health status as worse and a $4.5 \%$ not responding. Pearson's chi-square analysis was not statistically significant $p>0.05(p=0.713)$, rejecting the relationship proposed between the type of residence and the increase in BMI.

\section{Nutritional condition}

The participants were asked if they had made changes in terms of nutrition during the year, to which 74 (79.6\%) answered that their nutritional habits had not changed. A total of $17(18.3 \%)$ reported having started a diet or simply having incorporated more fruits or vegetables into their diet. Of these students, $15(88.24 \%)$ were women and only two were men. Two of the participants did not answer the question.

Regarding whether they engaged in physical activity, 45 students (48.4\%) reported going to the gym regularly during the academic year, while the remaining 46 (49.5\%) did not go to the gym at all.

Regarding alcoholic beverages, 14 students (15.1\%) said that they drank alcohol frequently while $77(82.8 \%)$ did not report alcohol consumption. Table 4.

Table 1. Characteristics of Student Population in the study sample

\begin{tabular}{|c|c|c|c|}
\cline { 2 - 4 } \multicolumn{1}{c|}{} & Total & Girls & Boys \\
\hline N (\%) & $93(100 \%)$ & $80(86 \%)$ & $13(14 \%)$ \\
\hline Age (years) & $19.99 \pm 3.99$ & $20,23 \pm 4,26$ & $18,46 \pm 0,88$ \\
\hline $\begin{array}{c}\text { Residence along } \\
\text { the course }\end{array}$ & $\begin{array}{c}\text { Living with their } \\
\text { parents }\end{array}$ & $\begin{array}{c}\text { Living in } \\
\text { residence }\end{array}$ & $\begin{array}{c}\text { Living alone or } \\
\text { sharing a flat }\end{array}$ \\
\hline & 21 & 23 & 49 \\
\hline
\end{tabular}




\begin{tabular}{|c|c|c|c|}
\hline $\begin{array}{c}\text { N } \\
\%\end{array}$ & $22,6 \%$ & $24,7 \%$ & $52,7 \%$ \\
\hline \multicolumn{2}{|c|}{ BMI } & \multicolumn{2}{|c|}{} \\
\hline BMI-1 begining & Girls & Boys & p-value \\
\cline { 2 - 4 } course & $21,98 \pm 3,67$ & $23,88 \pm 5,19$ & $p<0.156$ \\
\hline \multirow{2}{*}{ BMI-2 mid-course } & Girls & Boys & $p<0.015$ \\
\cline { 2 - 4 } & $22,39 \pm 4,09$ & $25,61 \pm 5,69$ & \\
\hline BMI-3 at the end of & Girls & Boys & $p<0.009$ \\
\cline { 2 - 4 } the course & $22,64 \pm 4,23$ & $26,28 \pm 6,053$ & \\
\hline
\end{tabular}

BMI: Body mass index

Table 2. BMI and Place where they live during the course

\begin{tabular}{|c|c|c|c|c|c|}
\hline Variable & & $\mathbf{N}$ & Mean & SD & p-Value \\
\hline \multirow{4}{*}{$\begin{array}{l}\text { BMI-1 } \\
\text { begining } \\
\text { course }\end{array}$} & living alone & 39 & 21,94 & $\pm 2,83$ & 0,733 \\
\hline & living at residence & 21 & 22,78 & $\pm 4,27$ & \\
\hline & living at home with their parents & 14 & 22,27 & $\pm 5,83$ & \\
\hline & Total & 74 & 22,24 & $\pm 3,92$ & \\
\hline \multirow{4}{*}{$\begin{array}{l}\text { BMI-2 } \\
\text { mid-course }\end{array}$} & living alone & 49 & 22,49 & $\pm 3,16$ & 0,660 \\
\hline & living at residence & 22 & 23,00 & $\pm 4,92$ & \\
\hline & living at home with their parents & 20 & 23,55 & $\pm 6,44$ & \\
\hline & Total & 91 & 22,85 & $\pm 4,46$ & \\
\hline \multirow{3}{*}{$\begin{array}{l}\text { BMI- } 3 \\
\text { At the end of } \\
\text { the course }\end{array}$} & living alone & 48 & 22,83 & $\pm 3,35$ & 0,612 \\
\hline & living at residence & 22 & 23,05 & $\pm 4,84$ & \\
\hline & living at home with their parents & 21 & 24,04 & $\pm 6,80$ & \\
\hline
\end{tabular}




\begin{tabular}{|l|r|r|r|r|}
\hline Total & 91 & 23,16 & $\pm 4,67$ & \\
\hline
\end{tabular}

S.D. = standard deviation, $\mathrm{N}=$ number of subjects.

Table 3. Data of subjects as a function of body mass index values.

\begin{tabular}{|c|c|c|c|c|}
\hline BMI & $\mathbf{N}$ & $\%$ & $\mathbf{N}$ & $\%$ \\
\hline & \multicolumn{2}{|c|}{$\begin{array}{c}\text { Beginning of } \\
\text { course }\end{array}$} & \multicolumn{2}{c|}{$\begin{array}{c}\text { The end of } \\
\text { course }\end{array}$} \\
\hline Underweight & 12 & $16,4 \%$ & 9 & $10,0 \%$ \\
\hline Healthy weight & 45 & $61,6 \%$ & 55 & $61,1 \%$ \\
\hline Overweight & 13 & $17,8 \%$ & 18 & $20,0 \%$ \\
\hline Obesity & 3 & $4,2 \%$ & 8 & $8,9 \%$ \\
\hline
\end{tabular}

$\mathrm{N}=$ number of subjects

Table 4. Indicator of perception of their state of Health to beginning and the end of course

\begin{tabular}{|c|c|c|c|c|c|}
\hline \multirow{2}{*}{$\begin{array}{c}\text { Beginning } \\
\text { of course } \\
\quad \mathrm{N},(\%)\end{array}$} & $\begin{array}{c}\text { Heath to be } \\
\text { very good }\end{array}$ & $\begin{array}{l}\text { Health as } \\
\text { good }\end{array}$ & $\begin{array}{c}\text { Health was } \\
\text { average }\end{array}$ & $\begin{array}{c}\text { Do not know, } \\
\text { no answer }\end{array}$ & \\
\hline & $22(23.7 \%)$ & $40(43 \%)$ & $8(8.6 \%)$ & $23(24.7 \%)$ & \\
\hline \multirow[t]{2}{*}{$\begin{array}{c}\text { The end of } \\
\text { course }\end{array}$} & $\begin{array}{c}\text { Reporting } \\
\text { their health } \\
\text { was the same } \\
\text { as at the start } \\
\text { of the yea }\end{array}$ & $\begin{array}{l}\text { Perceived } \\
\text { their health to } \\
\text { be the same } \\
\text { throughout the } \\
\text { year }\end{array}$ & $\begin{array}{c}\text { Their state of } \\
\text { health had } \\
\text { improved }\end{array}$ & $\begin{array}{c}\text { Perceiving } \\
\text { their health as } \\
\text { worse }\end{array}$ & $\begin{array}{l}\text { Do not } \\
\text { know no } \\
\text { answer }\end{array}$ \\
\hline & $44(47,3 \%)$ & $4548.5 \%$ & $23(24.7 \%)$ & $17(18.3 \%)$ & $7(9,7 \%)$ \\
\hline $\begin{array}{c}\text { Other } \\
\text { changes } \\
\text { throughout }\end{array}$ & $\begin{array}{c}\text { Smokers or } \\
\text { began to } \\
\text { smoke }\end{array}$ & $\begin{array}{c}\text { Drinking more } \\
\text { alcohol than at } \\
\text { the star of }\end{array}$ & $\begin{array}{c}\text { Changes of } \\
\text { nutrition }\end{array}$ & $\begin{array}{l}\text { Reported } \\
\text { going to the } \\
\text { gym regularly }\end{array}$ & \\
\hline
\end{tabular}




\begin{tabular}{|c|c|c|c|c|}
\hline the year & & course & & \\
\hline $\mathrm{N},(\%)$ & $13(14 \%)$ & $14(15.1 \%)$ & 74 (79.6\%) & $\begin{array}{c}45 \text { students } \\
(48.4 \%)\end{array}$ \\
\hline
\end{tabular}

\section{Discussion}

The students' BMI increased from start to finish in their first year of study. This is consistent with studies in other student populations, where BMI values in the population have been shown to increase year after year, regardless of age and social or economic status [7,8,25-27]. College students adopt new lifestyles that involve higher caloric intake and a sedentary lifestyle, causing an increase in body weight. The increase in BMI is most evident towards the end of the academic year, which could be related to a more sedentary lifestyle and the pressure of final exams.

A healthy diet has been shown to play a key role in the lives of college students [28]. Those who live at home with their parents may find that their diet is more controlled. The group of students who live alone is possibly more affected by their type of residence and could be more prone to a greater increase in BMI. However, the individual analysis of each group did not reveal significant findings except in those who continue to live with their parents, which leads us to determine that other factors are the cause of this increase in BMI.

Few studies have examined the impact of the emergence of new responsibilities such as socioeconomic status $[29,30]$. Our data reveal a greater increase in BMI in boys than in girls, which is consistent with studies conducted in different populations and ages [31,32]. Changes in lifestyle associated with reaching the age of majority, lower levels of parental control, the independence of living alone, can generate these changes in eating habits that, in turn, can lead to weight gain in short periods. like an academic year. However, the statistically significant increase in BMI was detected in students who 
did not change their place of residence in the transition from high school to university, compared to those who live alone or in residences. Students residing in the dormitories have their dietary needs guaranteed even though they may skip meals. The last group, those who live alone, despite eating and making their own food, the quality of the meals or the repetition of types of food based on precooked dishes or poor quality foods can be the cause of weight gain. However, a reasonable number of our participants in all groups reported having acquired better eating habits, with higher consumption of fruits and vegetables. the quality of the meals or the repetition of types of food based on precooked dishes or poor quality foods can be the cause of weight gain. However, a reasonable number of our participants in all groups reported having acquired better eating habits, with higher consumption of fruits and vegetables. the quality of the meals or the repetition of types of food based on precooked dishes or poor quality foods can be the cause of weight gain. However, a reasonable number of our participants in all groups reported having acquired better eating habits, with higher consumption of fruits and vegetables.

An increase in alcohol and tobacco consumption was observed in all groups. Some studies have shown an association between smoking, low levels of physical activity and an increase in obesity [36], while other studies have found a relationship between obesity and alcohol intake regardless of sex and have shown that the BMI is inversely related to physical activity. in women and to self-perceived health in men [34]. On the contrary, several studies have not found an association between lack of physical activity, a sedentary lifestyle, alcohol and tobacco consumption, and weight gain [21,27]. According to these authors, first-year college students are young people who are still growing, which would explain the lack of direct association between these determinants and weight gain. Our data, however, lead us to believe that lower levels of activity and increased sedentary behaviors, along with inappropriate eating habits, are factors that influence weight gain, at least among our students. The results presented in this work suggest a slight weight gain among students who continue to live in the family home, regardless of age and sex. This trend may be a consequence of their food supply being catered for and, therefore, they show less concern about what they eat, compared to those who are in charge of managing both the kitchen and their finances.

It would be necessary to continue observing these students throughout the following academic years and examine how their weight and physical activity evolved and the changes in their eating and health habitsAuthors should discuss the results and how they can be interpreted from the perspective of previous studies and of the working hypotheses. The findings and their implications should be discussed in the broadest context possible. Future research directions may also be highlighted.

A limitation of the study is the self-report. Some bias related to self-reported information has been shown to exist, but the data are considered adequate for research purposes [35-36]. Estimated BMI values may result in lower measurements than those based on directly measured weight and height [21,28,37]. Other authors have found a high level of precision in data from self-reported surveys and direct measurements [36- 
38]. The data are reliable since we administered three surveys at three points during the year, where there was no variation in the height values, but the weight values did change. The respondents had no reason to make mistakes in their height and weight measurements.

The longitudinal design of our study meant that we lost some of the students during the year. The design is also a strength as it allowed us to see the evolution of BMI in a sufficient number of students to obtain meaningful data on the cause / effect of the increase in BMI. In addition, we had data from 93\% of the survey participants.

First-year nursing students study nutrition. This could have led them to change their dietary behavior, improve their consumption of fruits and vegetables, reduce their intake of sugary drinks, and increase physical activity, which was observed towards the end of the academic year.

\section{Conclusions}

The study revealed an increase in BMI in our study sample among first-year students. It occurs among all students regardless of age, sex, socioeconomic status.

Among the variables that explain this increase, it seems that those who continue to live in the same family nucleus have a greater increase than the rest who live alone or in residences.

It is necessary to delve deeper into the habits of these groups of students to determine the cause of this increase in BMI.

\section{Author Contributions:}

"Conceptualization, AV and AMM.; methodology, AV, JAG-CDF and JLMC ; software, X. -JJCA .; validation, AV, JJCA, FMR, LMCM, CMM and AMM; formal analysisJJCA and AMM.; investigation, AV resources, CDF, JLMC, FMR; writing-AV .; writing - review and editing, AV, and AMM.; visualization, JJCA, JAG, CDF, JLMC, FMR, LMCM, CMM, BPL and AMM

project administration, $\mathrm{AV}$

Funding: Thank the students for their participation. This work was supported by grant (2019-GRIN-26896, 2020-GRIN-29192).

Institutional Review Board Statement: The study was carried out in accordance with the Declaration of Helsinki, and the protocol was approved by the Ethics Committee of the Castilla-La Mancha Health Service under the number 178013/113.

Informed Consent Statement: Informed consent was obtained from all subjects involved in the study previously to begin the study.

Acknowledgments: our Acknowledgments to all the students who have participated in this study altruistically.

Conflicts of Interest: The authors declare that they have no conflict of interest.

\section{References}


1. Chourdakis M, Tzellos T, Papazisis G, Toulis K, Kouvelas D. Eating habits, health attitudes and obesity indices among medical students in northern Greece. Appetite. 2010 Dec;55(3):722-5. doi: 10.1016/j.appet.2010.08.013. Epub 2010 Aug 27. PMID: 20801179.

2. Hilger J, Loerbroks A, Diehl K. Eating behaviour of university students in Germany: Dietary intake, barriers to healthy eating and changes in eating behaviour since the time of matriculation. Appetite. 2017 Feb 1;109:100-107. doi: 10.1016/j.appet.2016.11.016. Epub 2016 Nov 15. PMID: 27864073.

3. Morseth B, Jørgensen L, Emaus N, Jacobsen BK, Wilsgaard T. Tracking of leisure time physical activity during 28 yr in adults: the Tromsø study. Med Sci Sports Exerc. 2011 Jul;43(7):1229-34. doi: 10.1249/MSS.0b013e3182084562. PMID: 21131860.

4. Davis J. Crossing customs: International students write on US college life and culture. 1193 ed Routledge. 2013

5. Dyson R, Renk K. Freshmen adaptation to university life: depressive symptoms, stress, and coping. J Clin Psychol. 2006 Oct;62(10):1231-44. doi: 10.1002/jclp.20295. PMID: 16810671.

6. Rogol AD, Clark PA, Roemmich JN. Growth and pubertal development in children and adolescents: effects of diet and physical activity. Am J Clin Nutr. 2000 Aug;72(2 Suppl):521S-8S. doi: 10.1093/ajcn/72.2.521S. PMID: 10919954.

7. Himes JH, Dietz WH. Guidelines for overweight in adolescent preventive services: recommendations from an expert committee. The Expert Committee on Clinical Guidelines for Overweight in Adolescent Preventive Services. Am J Clin Nutr. 1994 Feb;59(2):307-16. doi: 10.1093/ajcn/59.2.307. PMID: 8310979.

8. Vadeboncoeur C, Townsend N, Foster C. A meta-analysis of weight gain in first year university students: is freshman 15 a myth? BMC Obes. 2015 May 28;2:22. doi: 10.1186/s40608-015-0051-7. PMID: 26217537; PMCID: PMC4511069.

9. Hilger J, Loerbroks A, Diehl K. Eating behaviour of university students in Germany: Dietary intake, barriers to healthy eating and changes in eating behaviour since the time of matriculation. Appetite. 2017 Feb 1;109:100-107. doi: 10.1016/j.appet.2016.11.016. Epub 2016 Nov 15. PMID: 27864073.

10. bin Zaal AA, Musaiger AO, D'Souza R. Dietary habits associated with obesity among adolescents in Dubai, United Arab Emirates. Nutr Hosp. 2009 Jul-Aug;24(4):437-44. PMID: 19721923.

11. Musaiger AO, Bader Z, Al-Roomi K, D'Souza R. Dietary and lifestyle habits amongst adolescents in Bahrain. Food Nutr Res. 2011;55. doi: 10.3402/fnr.v55i0.7122. Epub 2011 Sep 9. PMID: 21912533; PMCID: PMC3171216.

12. El-Gilany AH, Elkhawaga G. Socioeconomic determinants of eating pattern of adolescent students in Mansoura, Egypt. Pan Afr Med J. 2012;13:22. Epub 2012 Oct 1. PMID: 23308327; PMCID: PMC3527023.

13. Mousa TY, Al-Domi HA, Mashal RH, Jibril MA. Eating disturbances among adolescent schoolgirls in Jordan. Appetite. 2010 Feb;54(1):196-201. doi: 10.1016/j.appet.2009.10.008. Epub 2009 Nov 10. PMID: 19900499.

14. Deliens T, Clarys P, De Bourdeaudhuij I, Deforche B. Determinants of eating behaviour in university students: a qualitative study using focus group discussions. BMC Public Health. 2014 Jan 18;14:53. doi: 10.1186/1471-2458-14-53. PMID: 24438555; PMCID: PMC3905922.

15. Cano Martín LM, Gonzalez-Gonzalez J, Mohedano-Moriano A, Viñuela A. Criado-Álvarez JJ. Estado nutricional de una población escolar en España y su relación con hábitos de alimentación y actividad física. Arch Latinoam Nutr 2019; 69 N 4, Doi 10.37527.2019.69.4.004

16. Ludy MJ, Tan SY, Leone RJ, Morgan AL, Tucker RM. Weight gain in first-semester university students: Positive sleep and diet practices associated with protective effects. Physiol Behav. 2018 Oct 1;194:132-136. doi: 10.1016/j.physbeh.2018.05.009. Epub 2018 May 10. PMID: 29753713.

17. Breslow RA, Guenther PM, Smothers BA. Alcohol drinking patterns and diet quality: the $1999-2000 \mathrm{National} \mathrm{Health} \mathrm{and} \mathrm{Nu-}$ trition Examination Survey. Am J Epidemiol. 2006 Feb 15;163(4):359-66. doi: 10.1093/aje/kwj050. Epub 2006 Jan 4. PMID: 16394204.

18. Gorgulho B, Marchioni DM, Conceição AB, Steluti J, Mussi MH, Nagai-Manelli R, Teixeira LR, Luz AA, Fischer FM. Quality of diet of working college students. Work. 2012;41 Suppl 1:5806-9. doi: 10.3233/WOR-2012-0958-5806. PMID: 22317694.

19. St-Onge MP, Roberts AL, Chen J, Kelleman M, O'Keeffe M, RoyChoudhury A, Jones PJ. Short sleep duration increases energy intakes but does not change energy expenditure in normal-weight individuals. Am J Clin Nutr. 2011 Aug;94(2):410-6. doi: 10.3945/ajcn.111.013904. Epub 2011 Jun 29. PMID: 21715510; PMCID: PMC3142720.

20. Deliens T, Clarys P, De Bourdeaudhuij I, Deforche B. Determinants of eating behaviour in university students: a qualitative study using focus group discussions. BMC Public Health. 2014 Jan 18;14:53. doi: 10.1186/1471-2458-14-53. PMID: 24438555; PMCID: PMC3905922.

21. Al-Hazzaa HM, Musaiger AO, Abahussain NA, Al-Sobayel HI, Qahwaji DM. Lifestyle correlates of self-reported sleep duration among Saudi adolescents: a multicentre school-based cross-sectional study. Child Care Health Dev. 2014 Jul;40(4):533-42. doi: 10.1111/cch.12051. Epub 2013 Mar 22. PMID: 23521148.

22. Henderson RM. The bigger the healthier: are the limits of BMI risk changing over time? Econ Hum Biol. 2005 Dec;3(3):339-66. doi: 10.1016/j.ehb.2005.08.001. Epub 2005 Oct 3. PMID: 16202670; PMCID: PMC1414803.

23. Linares C, Su D. Body mass index and health among Union Army veterans: 1891-1905. Econ Hum Biol. 2005 Dec;3(3):367-87. doi: 10.1016/j.ehb.2005.06.002. Epub 2005 Jul 19. PMID: 16046203.

24. Banna JC, Buchthal OV, Delormier T, Creed-Kanashiro HM, Penny ME. Influences on eating: a qualitative study of adolescents in a periurban area in Lima, Peru. BMC Public Health. 2016 Jan 15;16:40. doi: 10.1186/s12889-016-2724-7. PMID: 26772177; PMCID: PMC4714484. 
25. Al-Kilani H, Waly M, Yousef R. Trends of Obesity and Overweight among College Students in Oman: A cross sectional study. Sultan Qaboos Univ Med J. 2012 Feb;12(1):69-76. doi: 10.12816/0003090. Epub 2012 Feb 7. PMID: 22375261; PMCID: PMC3286720.

26. Nojomi M, Najamabadi S. Obesity among university students, Tehran, Iran. Asia Pac J Clin Nutr. 2006;15(4):516-20. PMID: 17077068.

27. Trujillo-Hernández B, Vásquez C, Almanza-Silva JR, Jaramillo-Virgen ME, Mellin-Landa TE, Valle-Figueroa OB, Pérez-Ayala R, Millán-Guerrero RO, Prieto-Díaz-Chávez E, Newton-Sánchez O. Frecuencia y factores de riesgo asociados a sobrepeso y obesidad en universitarios de Colima, México [The frequency of risk factors associated with obesity and being overweight in university students from Colima, Mexico]. Rev Salud Publica (Bogota). 2010 Apr;12(2):197-207. Spanish. doi: 10.1590/s012400642010000200003. PMID: 21031230.

28. Nola IA, Jelinić JD, Matanić D, Pucarin-Cvetković J, Bergman Marković B, Senta A. Differences in eating and lifestyle habits between first- and sixth-year medical students from Zagreb. Coll Antropol. 2010 Dec;34(4):1289-94. PMID: 21874711.

29. Chao CY, Shih CC, Wang CJ, Wu JS, Lu FH, Chang CJ, Yang YC. Low socioeconomic status may increase the risk of central obesity in incoming university students in Taiwan. Obes Res Clin Pract. 2014 May-Jun;8(3):e201-98. doi: 10.1016/j.orcp.2012.07.002. PMID: 24847662.

30. Seubsman SA, Lim LL, Banwell C, Sripaiboonkit N, Kelly M, Bain C, Sleigh AC. Socioeconomic status, sex, and obesity in a large national cohort of 15-87-year-old open university students in Thailand. J Epidemiol. 2010;20(1):13-20. doi: 10.2188/jea.je20090014. Epub 2009 Nov 21. PMID: 19934589; PMCID: PMC3900775.

31. Mayer M, Gleiss A, Häusler G, Borkenstein M, Kapelari K, Köstl G, Lassi M, Schemper M, Schmitt K, Blümel P. Weight and body mass index (BMI): current data for Austrian boys and girls aged 4 to under 19 years. Ann Hum Biol. 2015 Jan;42(1):45-55. doi: 10.3109/03014460.2014.907444. Epub 2014 Apr 24. PMID: 24761986.

32. Bener A, Kamal AA. Growth patterns of Qatari school children and adolescents aged 6-18 years. J Health Popul Nutr. 2005 Sep;23(3):250-8. PMID: 16262022.

33. Di Milia L, Vandelanotte C, Duncan MJ. The association between short sleep and obesity after controlling for demographic, lifestyle, work and health related factors. Sleep Med. 2013 Apr;14(4):319-23. doi: 10.1016/j.sleep.2012.12.007. Epub 2013 Feb 16. PMID: 23419528.

34. Lahti-Koski M, Pietinen P, Heliövaara M, Vartiainen E. Associations of body mass index and obesity with physical activity, food choices, alcohol intake, and smoking in the 1982-1997 FINRISK Studies. Am J Clin Nutr. 2002 May;75(5):809-17. doi: 10.1093/ajcn/75.5.809. PMID: 11976153.

35. Brener ND, Eaton DK, Lowry R, McManus T. The association between weight perception and BMI among high school students. Obes Res. 2004 Nov;12(11):1866-74. doi: 10.1038/oby.2004.232. PMID: 15601984. 